\title{
Enteropatia proliferativa em eqüinos
}

\author{
Proliferative enteropathy in horses
}

\author{
Núbia Resende de MacêdoI Ghanem Al-Ghamdi ${ }^{\mathrm{II}}$ Connie Jane Gebhart ${ }^{\mathrm{III}}$ \\ Roberto Maurício Carvalho Guedes ${ }^{\mathrm{I}^{*}}$
}

\section{- REVISÃO BIBLIOGRÁFICA -}

\section{RESUMO}

Enteropatia proliferativa (EP), causada pela Lawsonia intracellularis, tem sido descrita em eqüinos jovens. A maioria dos relatos de EP em eqüinos é proveniente da América do Norte. Não existe ainda relato desta enfermidade em eqüinos na América Latina, apesar de a distribuição mundial da enfermidade em suínos. Portanto, é bastante provável que a EP esteja sendo negligenciada no diagnóstico de diarréias em potros desmamados. Esta revisão enfoca aspectos gerais sobre a infecção, abrangendo desde a etiologia, a epidemiologia, a patogenia, os sinais clínicos, as lesões anátomo e histopatológicas, o diagnóstico e o tratamento, alertando sobre a potencial importância de $\mathbf{L}$. intracellularis como possível agente causal de diarréia em potros desmamados.

Palavras-chave: Enteropatia proliferativa, eqüinos, Lawsonia intracellularis.

\section{ABSTRACT}

Proliferative enteropathy (PE), which is caused by Lawsonia intracellularis, has been recently described in young horses. The majority of horse PE cases have been reported in North America. Despite the fact that PE in swine has a worldwide distribution, there has not been any report of this disease in horse in Latin America yet. Therefore, it is very likely that $\mathbf{L}$. intracellularis has been neglected on diagnosis of diarrhea in weanling foals. This review highlights general aspects about the infection, including etiology, epidemiology, pathogenesis, clinical signs, gross and histological lesions, diagnosis and treatment, and warns about the potential importance of $\boldsymbol{L}$. intracellularis as possible causative agent of diarrhea in weanling foals.

Key words: Proliferative enteropathy, horses, Lawsonia intracellularis.

\section{INTRODUÇÃO}

A enteropatia proliferativa (EP) é uma doença entérica transmissível que afeta diversas espécies animais, especialmente suínos. A EP possui distribuição mundial e o agente etiológico foi recentemente identificado e classificado como Lawsonia intracellularis, uma bactéria intracelular obrigatória (McORIST et al., 1995a).

As duas espécies mais afetadas pela EP são o suíno e o hamster (LAWSON \& GEBHART, 2000). Em ambas, a doença pode ser clinicamente grave. Em outras espécies animais, tais como o veado (DROLET et al., 1996), o cão (COLLINS \& LIBAL, 1983; FEARY et al., 2007), a raposa (ERIKSEN et al., 1990), o cobaio (ELWELL et al., 1981), o rato (VANDENBERGHE et al., 1985), o furão (FOX \& LAWSON, 1988), o macaco (KLEIN et al., 1999), o coelho (MOON et al., 1974), o

\footnotetext{
'Departamento de Clínica e Cirurgia Veterinárias, Universidade Federal de Minas Gerais (UFMG), 31270-901, Belo Horizonte, MG, Brasil. E-mail: guedes@vet.ufmg.br. *Autor para correspondência.

"Departament of Clinical Studies, College of Veterinary Medicine and Animal Resources, King Faisal University. P O Box 55054. Al-Ahsa 31982. Arábia Saudita.

IIIDepartmentof Veterinary and Biomedical Science. College of Veterinary Medicine. University of Minnesota. St Paul, MN 55108, EUA.
} 
emu (LEMARCHAND et al., 1997) e o avestruz (COOPER et al., 1997), a doença geralmente ocorre como casos isolados ou em pequenos surtos ocasionais (LAWSON \& GEBHART, 2000). DNA de $\boldsymbol{L}$. intracellularis foi recentemente detectado em fezes diarréicas de bezerros, porco-espinho e girafa (HERBST et al., 2003).

A EP tem sido descrita esporadicamente em eqüinos, sendo que não há estudo epidemiológico sobre a prevalência da enfermidade. Um projeto pioneiro referente ao estudo da ocorrência da EP em criatórios de eqüinos do Estado de Minas Gerais está sendo iniciado na Escola de Veterinária da Universidade Federal de Minas Gerais (UFMG), sob a coordenação do professor Roberto M. C. Guedes. O primeiro relato de EP em eqüinos foi feito por DUHAMEL \& WHEELDON (1982), em um potro Árabe de seis meses de idade. Desde 1996, foram descritos vários relatos de casos individuais na América do Norte (WILLIAMS et al., 1996; FRANK et al., 1998; SCHUMACHER et al., 2000; BIHR, 2003; ATHERTON \& McKENZIE III, 2006; DAUVILLIER et al., 2006; SAMPIERI et al., 2006) e surtos em três haras no Canadá (LAVOIE et al., 2000). Casos na Austrália (McCLINTOCK \& COLLINS, 2004) e outros dois na Europa (DEPREZ et al., 2005; WUERSCH et al., 2006) foram relatados.

AL-GHAMDI (2003) conseguiu reproduzir a EP em potros de dois meses de idade, usando homogeneizado de mucosa intestinal obtido de suínos experimentalmente infectados com $\boldsymbol{L}$. intracellularis e também usando cultura pura de $\mathbf{L}$. intracellularis.

Pouco se conhece sobre a prevalência de EP entre a população eqüina e os mecanismos de patogenicidade de $\boldsymbol{L}$. intracellularis nesta espécie. Apesar de a maioria dos relatos de EP em eqüinos serem provenientes da América do Norte, isso não indica, necessariamente, que os outros países sejam livres da doença. Não existe ainda relato desta enfermidade em eqüinos na América Latina. O objetivo deste trabalho é discutir a EP em eqüinos e alertar sobre a potencial importância de $\boldsymbol{L}$. intracellularis como possível agente causal de diarréia em potros desmamados no Brasil.

\section{DESENVOLVIMENTO}

\section{Epidemiologia}

A epidemiologia da EP em eqüinos é praticamente desconhecida. É muito provável que a doença não esteja sendo diagnosticada nesta espécie, considerando a restrita disponibilidade de testes diagnósticos e a não-inclusão desta enfermidade no diagnóstico diferencial em casos de diarréia ou subdesenvolvimento de potros desmamados (BIHR,
2003). A contaminação do eqüino, como nas outras espécies susceptíveis, é fecal-oral, entretanto, o fato de que várias espécies animais possam ser afetadas pela EP torna a epidemiologia da doença bastante complexa (AL-GHAMDI, 2003). Relato de (SMITH et al., 2000) indicou que camundongos são afetados pela EP e, portanto, há a possibilidade de serem reservatórios e disseminadores da bactéria entre eqüinos. Outros animais, como veados, pássaros, cães e gatos, podem estar atuando como reservatórios da doença (LAVOIE et al., 2000; LAWSON \& GEBHART, 2000; FEARY et al., 2007). Finalmente, não se deve descartar a possibilidade de a égua, como portadora, ser fonte de infecção de $\boldsymbol{L}$. intracellularis para potros susceptíveis (AL-GHAMDI, 2003).

Até a presente data, com exceção de um relato na Austrália e outros na Suíça e Bélgica, todos os casos de EP em eqüinos descritos na literatura ocorreram na América do Norte (Canadá e Estados Unidos) (AL-GHAMDI, 2003). Entretanto, este fato não necessariamente indica ausência da enfermidade em outros países, já que, em suínos, segundo LAWSON \& GEBHART (2000), a doença tem distribuição mundial, apesar de a transmissão do agente entre diferentes espécies ainda não ter sido demonstrada (SMITH et al., 2000).

Assim como os suínos, eqüinos parecem ser mais susceptíveis à infecção logo após o desmame (AL-GHAMDI, 2003; WUERSCH et al., 2006). A faixa etária de potros afetados pode variar de três a nove meses (DUHAMEL \& WHEELDON, 1982; WILLIAMS et al., 1996; FRANK et al., 1998; BREES et al., 1999; LAVOIE et al., 2000; SCHUMACHER et al., 2000; LAVOIE \& DROLET, 2002; WUERSCH et al., 2006). Porém, este fato não comprova a associação entre desmame e ocorrência de EP em eqüinos. Outros fatores podem estar envolvidos, incluindo o tempo de exposição à bactéria, a quantidade de bactéria a que o potro foi exposto e o estado imune do animal. A EP parece ser mais freqüente em potros no outono e no início do inverno. Se isso reflete prevalência estacional, faixa etária, ou práticas de manejo como o desmame, ainda não se sabe (AL-GHAMDI, 2003; WUERSCH et al., 2006).

FRANK et al. (1998) relatam o caso de um potro quarto de milha de Minnesota (EUA), com seis meses de idade, no qual o estresse e a idade podem ter contribuído para o desenvolvimento de enteropatia proliferativa por $\boldsymbol{L}$. intracellularis. O potro havia sido desmamado recentemente, vacinado, vermifugado e estava sendo intensivamente treinado para sua primeira apresentação hípica. $\mathrm{O}$ animal recebeu somente terapia 
de suporte, sem drogas antimicrobianas, e sua condição piorou até o óbito.

Em sua tese de doutoramento nos Estados Unidos, AL-GHAMDI (2003) coletou amostras de nove criatórios de eqüinos dos Estados da Flórida, de Kentucky e de Minnesota no período de 1999 a 2001 para avaliação da eliminação de $\boldsymbol{L}$. intracellularis nas fezes e presença de anticorpos séricos específicos, além de informações epidemiológicas por meio de questionário detalhado. De 46 potros desmamados, entre três e 12 meses de idade, oito animais, provenientes de três criatórios com histórico de EP clínica, foram soropositivos na técnica de imunoperoxidase em lâmina e um deles veio a óbito em decorrência de extensas lesões intestinais características desta enfermidade. Além deste potro, somente outros dois, do total de oito soropositivos, apresentaram quadro clínico sugestivo de EP. Nenhuma destas três propriedades estava localizada perto de criatórios de suínos.

Patogênese

A etiopatogênese de enteropatia proliferativa por L. intracellularis tem sido extensivamente estudada em suínos. Experimentalmente, quando suínos são inoculados com culturas puras de células de $\boldsymbol{L}$. intracellularis ou com homogeneizado de mucosa intestinal obtido de suínos experimentalmente ou naturalmente infectados, o tempo entre a inoculação e o desenvolvimento dos sinais clínicos, caracterizados por diarréia, começam a ser observados de sete a 10 dias após a inoculação (KNITTEL et al., 1998; GUEDES et al., 2002a). Lesões graves à necropsia são vistas dentro de aproximadamente 21 dias. Enterócitos das criptas em divisão são o principal alvo das bactérias (HOTCHKISS et al., 1996). A eliminação de bactérias nas fezes foi observada a partir de três dias (GUEDES, 2002) e até 12 semanas após inoculação (GUEDES et al., 2002b, GUEDES \& GEBHART, 2003).

Pouco se sabe sobre os mecanismos celulares de infecção pela $\mathbf{L}$. intracellularis. Estudos in vitro (McORIST et al., 1995b) demonstraram que 10 minutos após exposição à bactéria esta pode ser encontrada em íntimo contato com a membrana de células eucariotas permissíveis à infecção. Uma hora após a infecção, a bactéria pode ser encontrada em vacúolos no citoplasma de células eucariotas. Três horas após a inoculação, a bactéria é observada livremente no citoplasma de células infectadas. A bactéria então se multiplica no citoplasma celular por divisão binária e, cinco a 10 dias após a infecção, protusões celulares repletas de bactérias se rompem, liberando-as no meio extracelular.
AL-GHAMDI (2003) reproduziu EP em cinco potros de dois meses de idade usando homogeneizado de mucosa de suínos afetados por EP e em um sexto potro com cultura pura de $\mathbf{L}$. intracellularis obtida de suínos. Os potros foram eutanasiados 22 dias após a inoculação e depois foram necropsiados. Fragmentos de intestino foram coletados para histopatologia e imunoistoquímica. Somente um dos animais inoculados com homogeneizado de mucosa apresentou alterações clínicas, macroscópicas e histopatológicas típicas de EP. Entretanto, a presença de $\mathbf{L}$. intracellularis foi confirmada em todos eles pelas técnicas de imunoistoquímica e/ou reação em cadeia da polimerase (PCR). O animal inoculado com cultura pura apresentou lesões clínicas, macroscópicas e histopatológicas típicas de EP. Desse modo, o papel de $\mathbf{L}$. intracellularis na etiopatogenia da EP em eqüinos foi estabelecido.

\section{Sinais clínicos}

Em eqüinos enfermos, os sinais clínicos variam e podem incluir anorexia, letargia, depressão, perda de peso e emaciação em casos subagudos e crônicos, e diarréia aquosa profusa em casos agudos com curso de dois a 10 dias até o óbito, se não tratados (DUHAMEL \& WHEELDON, 1982; WILLIAMS et al., 1996; FRANK et al., 1998, LAVOIE et al., 1998; ALGHAMDI, 2003; BIHR, 2003; WUERSCH et al., 2006). Sinais de febre (acima de $38.0^{\circ} \mathrm{C}$ ), desidratação leve à grave e anemia discreta foram vistos em vários casos (WILLIAMS et al., 1996; AL-GHAMDI, 2003; BIHR, 2003; WUERSCH et al., 2006). Sinais de cólica, com graus variados de dor abdominal, e edema subcutâneo ventral decorrente da hipoproteinemia podem acontecer precocemente no curso da diarréia (LAVOIE et al., 1998; SCHUMACHER et al., 2000; AL-GHAMDI, 2003; BIHR, 2003). Sinais de inflamação, tais como leucocitose, neutrofilia, linfocitose, observados no leucograma, e hiperfibrinogenemia são usualmente detectados (FRANK et al., 1998; LAVOIE et al., 1998; AL-GHAMDI, 2003; BIHR, 2003; WUERSCH et al., 2006). O perfil de bioquímica sérica revela, comumente, hipocloremia, hiponatremia, azotemia, marcante hipoproteinemia e acidose metabólica na hemogasometria $\left(\mathrm{HCO}_{3}\right.$ e $\left.\mathrm{pH}\right)$ (FRANK et al., 1998; LAVOIE et al., 1998; SCHUMACHER et al., 2000; AL-GHAMDI, 2003; BIHR, 2003; WUERSCH et al., 2006). Além disso, a concentração sérica de creatinina (CK), a atividade enzimática da aspartato amino transferase (AST) e da lactato desidrogenase (LDH) podem estar aumentadas (WUERSCH et al., 2006). Valores numéricos de parâmetros laboratoriais observados em 11 eqüinos com EP comparados com valores de referência podem ser observados na tabela 1 (SAMPIERI et al., 2006). Ultra- 
Tabela 1 - Hematologia e avaliação bioquímica sérica de 11 potros, entre quatro e nove meses de idade, atendidos Hospital Veterinário da Universidade Estadual de Ohio (EUA), no período de janeiro de 2001 a novembro de 2004, que apresentaram quadro de enteropatia proliferativa (EP) (SAMPIERI et al., 2006).

\begin{tabular}{|c|c|c|c|}
\hline & Valores de eqüinos com EP & Mediana & Valores referência* \\
\hline Proteínas totais $\left(\mathrm{g} \mathrm{l}^{-1}\right)$ & $22-71$ & 29 & $64-79$ \\
\hline Albumina ( $\mathrm{g} \mathrm{l}^{-1}$ ) & $10-22$ & 12 & $28-36$ \\
\hline Globina $\left(\mathrm{g} \mathrm{l}^{-1}\right)$ & $12-54$ & 18 & $36-43$ \\
\hline Leucócitos $\left(\mathrm{x} 10^{9} \mathrm{l}^{-1}\right)$ & $4,9-21,2$ & 14 & $4,6-10,6$ \\
\hline Pressão oncótica (mmHg) & $5,7-8,3$ & 7,9 & $>12$ \\
\hline Cálcio total (mmol l-1) & $2,09-3,07$ & 2,28 & $2,78-3,25$ \\
\hline Sódio (mmol l-1) & $121-140$ & 128 & $132-142$ \\
\hline Cloro (mmol l-1) & 83-105 & 93 & $97-105$ \\
\hline Bicarbonato $\left(\mathrm{HCO}_{3}\right)\left(\mathrm{mmol} \mathrm{l}^{-1}\right)$ & $16-27$ & 21 & $21-31$ \\
\hline Fibrinogênio $\left(\mathrm{g} \mathrm{l}^{-1}\right)$ & 2,97-6,95 & 4,32 & $1,93-4,22$ \\
\hline Creatinina (umol l-1) & $61,8-353,6$ & 176,8 & $70,7-150,3$ \\
\hline Nitrogênio uréico sanguineo - BUN (mmol l-1) & $6,4-24,3$ & 11,1 & $4,6-9,6$ \\
\hline Creatinina Quinase (CK) (u l l $)$ & $77-13300$ & 438 & $150-360$ \\
\hline
\end{tabular}

* Valores referência utilizados no Laboratório de Patologia Clínica da Universidade Estadual de Ohio.

sonografia abdominal pode revelar espessamento anormal das paredes do intestino delgado (4 a 8mm, valor de referência igual ou menor que 3mm; REEF, 1998), cólon e ceco (SCHUMACHER et al., 2000; ALGHAMDI, 2003; SAMPIERI et al., 2006).

O principal achado laboratorial é a hipoproteinemia (DUHAMEL \& WHEELDON, 1982; WILLIAMS et al., 1996; FRANK et al., 1998; LAVOIE et al., 1998; SCHUMACHER et al., 2000; AL-GHAMDI, 2003; BIHR, 2003; WUERSCH et al., 2006). Segundo LAVOIE et al. (2000), BIHR (2003), e WUERSCH et al. (2006), a hipoproteinemia pode ser atribuída a alterações patológicas no trato gastrointestinal, provavelmente devido à má absorção e perda de proteínas para o lúmen intestinal. Outras alterações, tais como aumento da concentração sérica de CK e da atividade enzimática da AST e LDH, podem ser indicação de lesão muscular conseqüente ao catabolismo protéico ou hipóxia devido ao decúbito prolongado associado à hipovolemia (WUERSCH et al., 2006). Aumento na concentração de creatinina pode ser atribuído ao estado catabólico dos animais afetados (LAVOIE et al., 2000). Aumento nos valores da uréia sangüínea pode estar associado à redução da perfusão renal devido à desidratação e ao aumento do catabolismo protéico. Finalmente, a diarréia profusa que os animais doentes apresentam pode explicar a hiponatremia e a hipocloremia, e a anemia pode ser causada pela deficiência de ferro devido à má absorção (WUERSCH et al., 2006).

Patologia

Devido ao fato de somente um pequeno número de casos de EP ter sido confirmado em eqüinos na literatura, informações sobre lesões patológicas de EP nesta espécie permanecem escassas. Além disso, na maioria dos casos, lesões macroscópicas estão restritas ao intestino delgado (DUHAMEL \& WHEELDON, 1982; WILLIAMS et al., 1996; FRANK et al., 1998).

Dentre as lesões macroscópicas, a mais importante é o espessamento difuso da mucosa do duodeno, jejuno e íleo (Figura 1), que é atribuído à hiperplasia de criptas da mucosa e edema transmural (DUHAMEL \& WHEELDON, 1982; WILLIAMS et al., 1996; FRANK et al., 1998; SCHUMACHER et al., 2000; AL-GHAMDI, 2003; WUERSCH et al., 2006). As áreas afetadas podem ainda conter áreas de ulcerações confluentes cobertas por fibrina. O cólon distal e o reto podem conter fezes pastosas e fétidas (FRANK et al., 1998; WUERSCH et al., 2006).

Lesões histopatológicas geralmente são restritas ao intestino delgado. Marcante encurtamento das vilosidades intestinais pode ser visto ao exame histopatológico de fragmento de jejuno espessado (DUHAMEL \& WHEELDON, 1982; SCHUMACHER et al., 2000; AL-GHAMDI, 2003; WUERSCH et al., 2006). O epitélio das criptas geralmente encontra-se espesso e caracterizado por enterócitos colunares imaturos (Figura 2) com citoplasma basofílico vacuolizado e núcleo vesiculoso com nucléolo proeminente. A lâmina própria pode estar moderadamente expandida por infiltrado inflamatório predominantemente histiocitário (DUHAMEL \& WHEELDON, 1982; WILLIAMS et al., 1996; FRANK et al., 1998; SCHUMACHER et al., 2000; AL-GHAMDI, 2003; WUERSCH et al., 2006). No 


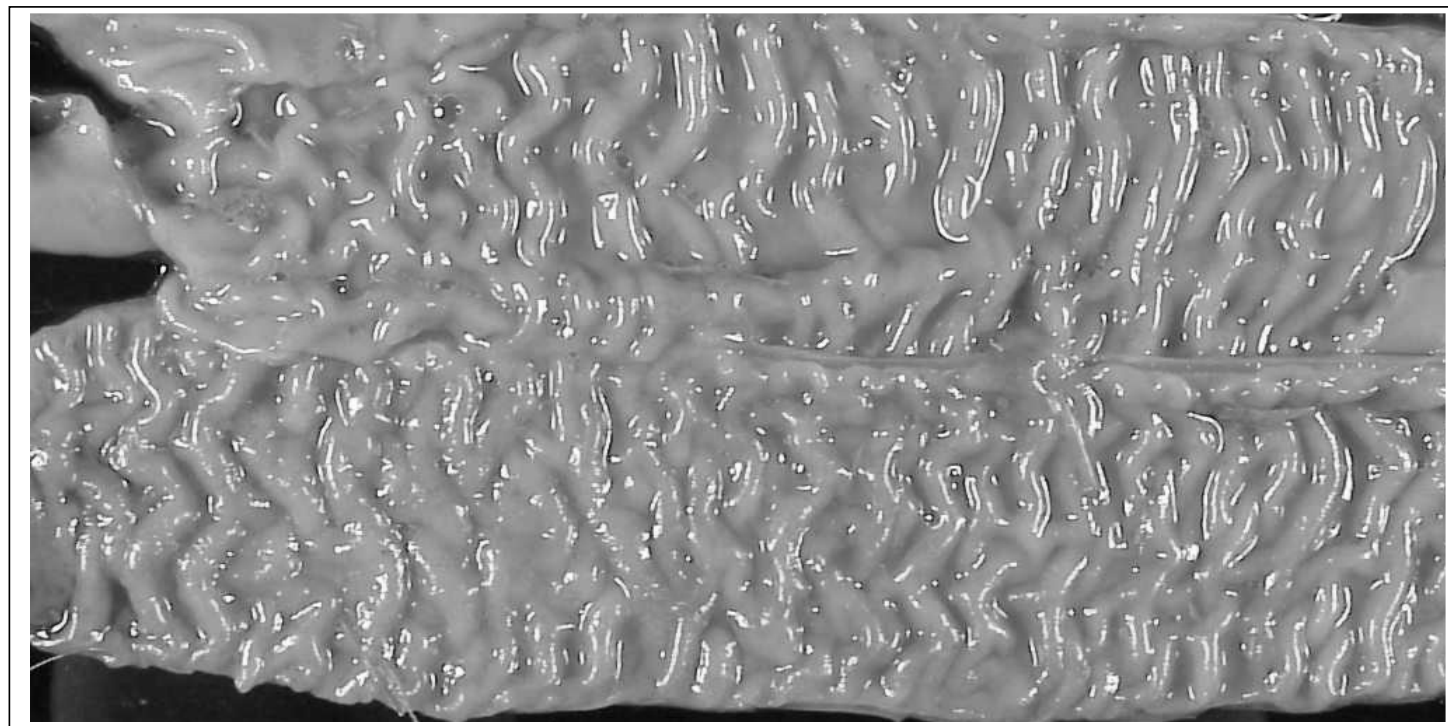

Figura 1 - Amostras de potro de seis meses de idade. Dois fragmentos de jejuno abertos longitudinalmente mostrando intenso espessamento de pregas transversais da mucosa, aspecto macroscópico sugestivo de enteropatia proliferativa. (Fonte: AL-GHAMDI, 2003).

entanto, o duodeno é o segmento do intestino delgado menos lesado (AL-GHAMDI, 2003).

Diagnóstico

O diagnóstico presuntivo de eqüinos infectados por $\boldsymbol{L}$. intracellularis pode ser feito com

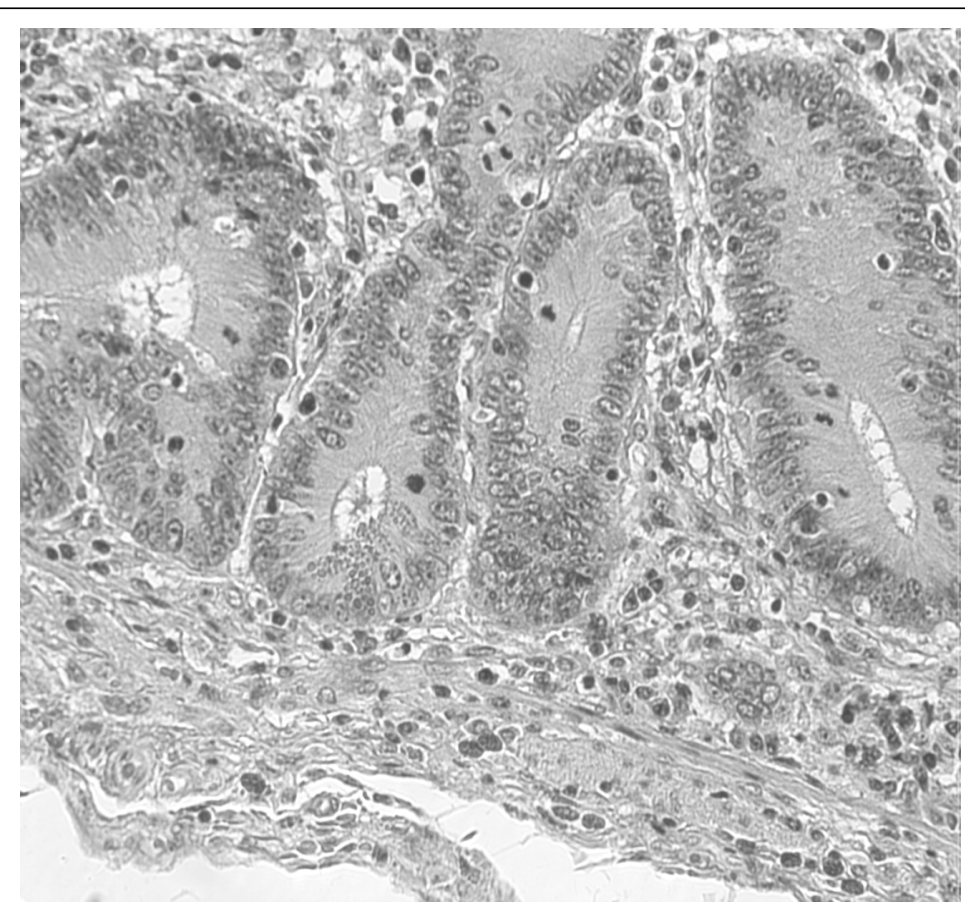

Figura 2 - Criptas intestinais de jejuno de potro da figura 1, demonstrando intensa hiperplasia de enterócitos, redução de células de Paneth e ausência de células caliciformes. Características histológicas típicas de enteropatia proliferativa. HE, 200x. (Fonte: AL-GHAMDI, 2003) base nos sinais clínicos, presença de hipoproteinemia e com a exclusão de infecções entéricas comuns (LAVOIE et al., 1998; AL-GHAMDI, 2003), discutidas a seguir. Entretanto, a maior parte dos diagnósticos é feita no exame post-morten dos casos suspeitos de EP, associado aos achados histopatológicos de lesões de áreas do intestino delgado (DUHAMEL \& WHEELDON, 1982; WILLIAMS et al., 1996; COOPER et al., 1997; FRANK et al., 1998; SCHUMACHER et al., 2000; ALGHAMDI, 2003; WUERSCH et al., 2006). Coloração pela prata (Warthin Starry, Levaditi ou Young modificado) pode ser usada para detectar a bactéria na parte apical do citoplasma de enterócitos durante exame ao microscópio óptico (WILLIAMS et al., 1996; COOPER et al., 1997; FRANK et al., 1998; ALGHAMDI, 2003; WUERSCH et al., 2006). Entretanto, essa coloração não é específica para $\boldsymbol{L}$. intracellularis (COOPER et al., 1997), por isso, deve haver uma associação entre as lesões histopatológicas e a presença do microrganismo intracelular corado pela prata. Microscopia eletrônica pode ser usada para visualizar bacilos retos ou curvos 
dentro do citosol de enterócitos (DUHAMEL \& WHEELDON, 1982; WILLIAMS et al., 1996; FRANK et al., 1998), mas ela tem custo elevado.

A L . intracellularis é uma bactéria extremamente difícil de se propagar em laboratório por requerer cultura de células em condições específicas de pressão de nitrogênio (83,2 \%), dióxido de carbono (8,8\%) e oxigênio (8.0\%) (LAWSON \& GEBHART, 2000; SCHUMACHER et al., 2000; AL-GHAMDI, 2003), sendo esta técnica disponível somente em poucas instituições de pesquisa do mundo (LAVOIE \& DROLET, 2002). Este fato pode explicar o limitado número de casos de EP em eqüinos na literatura.

O diagnóstico de EP usando imunoistoquímica (IHQ) (Figura 3) é considerado o método de escolha para detectar $\boldsymbol{L}$. intracellularis (WILLIAMS et al., 1996; FRANK et al., 1998; SCHUMACHER et al., 2000; ALGHAMDI, 2003) com sensibilidade de cerca de $88 \%$ (GUEDES et al., 2002a). AL-GHAMDI (2003), em estudo retrospectivo (1990 a 1998), documentou a ocorrência de EP em eqüinos em Minnesota. Foram examinadas secções intestinais parafinizadas utilizando imunoistoquímica com anticorpos monoclonais e policlonais específicos para $\boldsymbol{L}$. intracellularis. A partir deste estudo, a EP começou a ser considerada no diagnóstico diferencial de eqüinos com doença entérica não-responsiva. Testes específicos usando IHC podem ser requeridos para diagnóstico apropriado da doença após o exame post-mortem (AL-GHAMDI, 2003).

A utilização de métodos ante-mortem eficientes para detectar EP em eqüinos é necessária para que seja possível um tratamento específico e bem sucedido de indivíduos acometidos. Testes sorológicos, tais como teste de imunofluorescência indireta (IFA) e imunoperoxidase em monocamada de células (IPMA), foram bem-sucedidos, demonstrando alta sensibilidade (89\%) para detectar EP em suínos. Em um estudo de AL-GHAMDI (2003), foram realizadas otimização e aplicação de sorologia e PCR para estimar a prevalência de infecção por $\boldsymbol{L}$. intracellularis em eqüinos nos EUA, no período entre 1999-2001, como discutido anteriormente. Foram utilizados testes sorológicos, incluindo teste de imunofluorescência indireta em lâminas (slide-IFA), teste de imunoperoxidase em lâminas (slide-IPX) e IPMA.

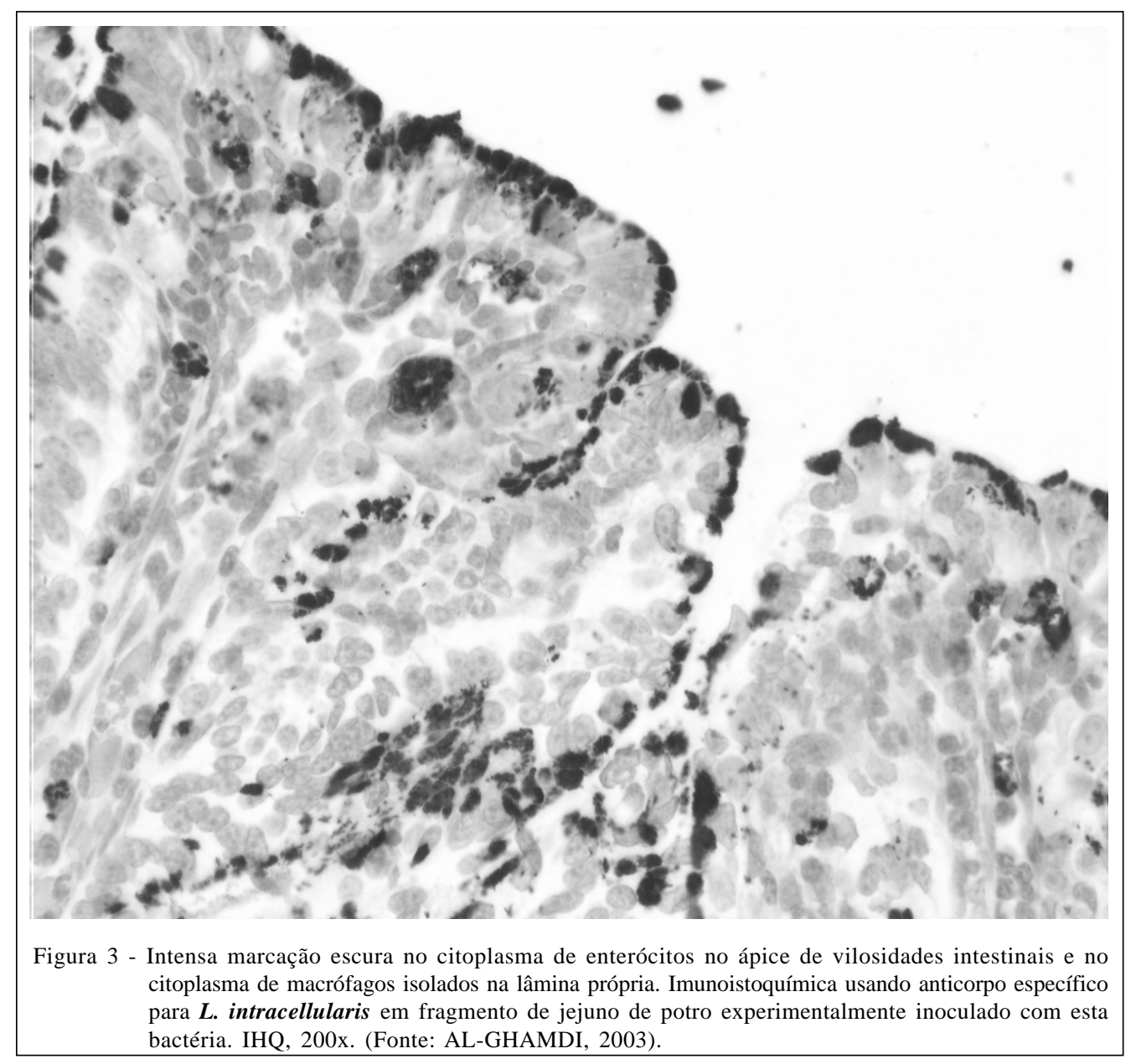

Ciência Rural, v.38, n.3, mai-jun, 2008. 
O teste molecular de PCR pode ser executado em amostra de fezes, apresentando sensibilidade que varia entre 40 e $85 \%$ em amostras de suínos (Guedes et al. 2002a). Esta última técnica já foi realizada por outros autores para detectar infecção por $\boldsymbol{L}$. intracellularis em potros enfermos (FRANK et al., 1998; LAVOIE et al., 2000; WUERSCH et al., 2006). O teste PCR de fezes no estudo de AL-GHAMDI (2003) foi menos sensível que a sorologia. Importante lembrar que a sorologia avalia a resposta imune frente à exposição ao antígeno em um período anterior, enquanto a PCR detecta efetiva eliminação de bactérias nas fezes.

LAVOIE et al. (2000) avaliaram sorologicamente amostras de plasma de sete potros com EP usando teste de imunofluorescência indireta para a presença de anticorpos contra $\boldsymbol{L}$. intracellularis. Todos eles continham anticorpos específicos contra esta bactéria intracelular, indicando uma exposição à bactéria e ilustrando o potencial benéfico da sorologia para o diagnóstico EP em eqüinos.

WILLIAMS et al. (1996) realizaram PCR de mucosa intestinal de uma potra de cinco meses de idade necropsiada em Minnesota. A visualização dos produtos da PCR evidenciou seqüências específicas para $\boldsymbol{L}$. intracellularis, e ainda foi realizada confirmação através de hibridização por Southern blot. Dessa forma, a PCR pode ser utilizada tanto em amostras de fezes quanto em intestinos suspeitos de apresentar infecção.

A utilização destes testes diagnósticos fornece informações valiosas sobre a prevalência deste organismo entre a população de eqüinos e o impacto na performance de eqüinos. Como os sinais clínicos da EP não são únicos entre as doenças entéricas, testes diagnósticos ante-mortem podem ajudar a diferenciar EP de outras doenças entéricas e a utilização de uma terapia antimicrobiana específica (AL-GHAMDI, 2003).

\section{Diagnóstico diferencial}

Várias condições podem levar à enteropatia com perda de proteínas via trato gastrointestinal, incluindo ulceração, antibioticoterapia e neoplasia, assim como causas infecciosas, tais como bactérias (Salmonella spp, Neorickettsia risticii, Clostridium spp), protozoários (Cryptosporidium spp), vírus e parasitas (BIHR, 2003).

Doenças bacterianas como salmonelose (Salmonella spp), colite por Clostridium spp e erliquiose (N.risticii) precisam ser pesquisadas em amostras para diagnóstico. Culturas fecais em série e/ ou detecção de DNA de Salmonella spp em fezes usando PCR são usadas para excluir salmonelose entérica (MURRAY \& SMITH, 2002). $N$. risticii pode ser detectada usando testes sorológicos, mas o diagnóstico só é confirmado pela visualização direta do microrganismo em monócitos circulantes ou no epitélio do cólon (JONES et al., 2000). Clostridium spp são excluídos usando culturas fecais para clostridios toxigênicos, detecção de toxinas clostridiais ou genes responsáveis pela expressão de toxinas usando PCR (MURRAY \& SMITH, 2002).

Doenças virais como rotavírus e adenovírus eqüino têm que ser excluídas. É possível identificar rotavírus por meio de isolamento em cultura de tecido ou pela demonstração do antígeno viral nas células epiteliais intestinais, por métodos de imunofluorescência (JONES et al., 2000). Infecção por adenovirus eqüino é predominante em potros imunodeprimidos. Doenças parasitárias causando diarréia, tais como Criptosporidiose, podem ser excluídas pela detecção de oocistos nas fezes ou IFA (MURRAY \& SMITH, 2002). Outras causas não-infecciosas de diarréia como drogas não-esteroidais (AINES), ulceração gástrica e antibioticoterapia devem ser excluídas. Isso pode ser possível por ser realizar cuidadosa anamnese (ALGHAMDI, 2003). A maioria das causas infecciosas de enterite em potros também causa diarréia; desde que o potro não sofra de diarréia, muitos dos patógenos podem ser excluídos (BIHR, 2003).

\section{Tratamento}

O início precoce do tratamento com o antibiótico apropriado influencia positivamente a taxa de recuperação de potros afetados por EP (ALGHAMDI, 2003), ainda mais se associado à terapia suporte. Fluidoterapia intravenosa para corrigir a desidratação e transfusão de plasma para corrigir a perda de proteínas podem ser necessárias (DUHAMEL \& WHEELDON, 1982; FRANK et al., 1998; LAVOIE et al., 1998; BIHR, 2003; WUERSCH et al., 2006). Agentes antiinflamatórios como flunexin meglumine $(0,25 \mathrm{mg}$ $\mathrm{kg}^{-1}$ p.v., intravenoso, 3 vezes por dia), dexametasona (40mg, via oral, diariamente) ou prednisona (1 $\mathrm{mg} \mathrm{kg}^{-1}$ p.v., via oral, diariamente), por um período de 14 dias, podem ser usadas para controlar a inflamação (FRANK et al., 1998; SCHUMACHER et al., 2000; BIHR, 2003; WUERSCH et al., 2006). Entretanto, o uso de terapia corticosteróide pode ser benéfico somente nas fases iniciais e o tratamento prolongado pode agravar a doença (AL-GHAMDI, 2003). Protetores de mucosa como cimetidina (5,0 $\mathrm{mg} \mathrm{kg}^{-1}$ p.v., intravenosa, 6-6 horas) podem ser usados (FRANK et al., 1998; SCHUMACHER et al., 2000; BIHR, 2003).

Devido à localização intracelular da $\boldsymbol{L}$. intracellularis, a terapia deve incluir um antibiótico que efetivamente penetre na membrana celular (BIHR, 
2003). A administração oral de uma combinação de eritromicina ( $25 \mathrm{mg} \mathrm{kg}^{-1}$ p.v., 6-6 horas) e rifampina (7$10 \mathrm{mg} \mathrm{kg}^{-1}$ p.v., 12-12 horas) é o tratamento de escolha para controle de $\boldsymbol{L}$. intracellularis (McORIST et al., 1995b; LAVOIE et al., 1998; SCHUMACHER et al., 2000; BIHR, 2003), já que a eritromicina/rifampina possuem concentrações intracelulares elevadas. $\mathrm{O}$ tratamento de 22 potros com suspeita de infecção por $\boldsymbol{L}$. intracellularis com eritromicina resultou em melhora rápida na condição geral e resolução dos sinais clínicos. Eritromicina foi administrada aos potros afetados por duas a quatro semanas (SCHUMACHER et al., 2000). Outros antibióticos como cloranfenicol ( $50 \mathrm{mg} \mathrm{kg}^{-1}$ p.v., via oral, 6-6 horas) (LAVOIE et al, 2000; ATHERTON \& McKENZIE III, 2006), doxiciclina (10 $\mathrm{mg} \mathrm{kg}^{-1}$ p.v., via oral, $12-12$ horas), Claritromicina $\left(7,5 \mathrm{mg} \mathrm{kg}^{-1}\right.$ p.v., via oral, $12-12$ horas) e azitromicina ( $10 \mathrm{mg} \mathrm{kg}^{-1}$ p.v., via oral, 12-12 horas) foram também eficazes na recuperação e na cura de potros afetados (ATHERTON \& McKENZIE III, 2006). Entretanto, LAVOIE et al. (2000), utilizando cloranfenicol nas mesmas concentrações acima citadas, em dois potros enfermos, observou recorrência de diarréia. Da mesma forma, sulfato de gentamicina ( $5 \mathrm{mg} / \mathrm{kg}$ p.v., intravenosa, $12-12$ horas) e penicilina procaínica (22.000 $\mathrm{UI} \mathrm{kg}^{-1}$, intramuscular, 1212 horas) (SCHUMACHER et al., 2000; WUERSCH et al., 2006) e oxitetraciclina $\left(6,6 \mathrm{mg} \mathrm{kg}^{-1}\right.$ p.v., intravenosa, 12-12 horas) (SAMPIERI et al., 2006) não foram eficazes na remissão da sintomatologia clínica.

\section{CONCLUSÃO}

Menos de 25 anos se passaram desde a primeira descrição de EP em eqüinos por DUHAMEL \& WHEELDON em 1982. Naquela época, a doença foi associada à infecção entérica por Campylobacter sputorum subsp. Mucosalis. Somente 15 anos depois, WILLIAMS et al., em 1996, usaram técnicas moleculares para identificar o agente causal de $\mathrm{EP}$ em eqüinos. O tempo ainda não foi suficiente para se compreender a complexidade da doença e são poucos os casos relatados. Dessa forma, o conhecimento da epidemiologia da EP em eqüinos é mínimo.

A doença no suíno, espécie mais bem estudada com relação a esta enfermidade, tem distribuição mundial, sendo muito comum no Brasil. É bastante provável que a EP esteja presente no Brasil, e em outros países da América Latina e do mundo, mas seja ainda negligenciada no diagnóstico de diarréias em potros desmamados. Portanto, estudos retrospectivos em arquivos de histopatologia e bancos de soro, e prospectivos usando métodos validados para diagnóstico pos-mortem e ante-mortem de EP são necessários para melhor definir a real importância da doença na espécie eqüina no Brasil e no mundo.

\section{REFERÊNCIAS}

AL-GHAMDI, G. Characterization of proliferative enteropathy in horses. 2003. 157f. Tese (PhD em Clínica) - of Veterinary Medicine, University of Minnesota, Minnesota, USA.

ATHERTON, R.P.; McKENZIE III, H.C. Alternative antimicrobial agents in the treatment of proliferative enteropathy in horses. Journal of Equine Veterinary Science, Fort Collins, v.26, p.535-541, 2006.

BREES, D.J. et al. Lawsonia intracellularis-like organism infection in a miniature foal. Journal of American Veterinary Medical Association, Schaumburg, v.215, p.511514, 1999.

BIHR, T.P. Protein-losing enteropathy caused by Lawsonia intracellularis in a weanling foal. Canadian Veterinary Journal, Ottawa, v.44, p.65-66, 2003.

COLLINS, J.E.; LIBAL, M.C. Proliferative enteritis in two pups. Journal of American Veterinary Medical Association, Schaumburg, v.193, p.886-889, 1983.

COOPER, D.M. et al. Diagnosis of proliferative enteritis in frozen and formalin-fixed, paraffin-embedded tissues from a hamster, horse, deer and ostrich using a specific multiplex PCR assay. Veterinary Microbiology, Amsterdan, v.54, p.47-62, 1997.

DAUVILLIER, J. et al. Diagnostic and epidemiological features of Lawsonia intracellularis enteropathy in 2 foals. Canadian Veterinary Journal, Ottawa, v. 47, p. 689-691, 2006.

DEPREZ, P. et al. Lawsonia intracellularis infection in a 12month-old colt in Belgium. Veterinary Record, Londres, v.157, p.774-776, 2005.

DROLET, R. et al. Proliferative enteritis in white-tailed deer. Journal Veterinary Diagnostic Investigation, Davis, v.8, p.250-253, 1996.

DUHAMEL, G.E.; WHEELDON, E.B. Intestinal adenomatosis in a foal. Veterinary Pathology, Auburn, v.19, p.447-450, 1982.

ELWELL, M.R. et al. Duodenal hyperplasia in a guinea pig. Veterinary Pathology, Auburn, v.18, p.136-139, 1981.

ERIKSEN, K. et al. Morphology and immunoperoxidase studies of intestinal adenomatosis in a blue fox, Alopex lagopus. Journal of Comparative Pathology, Londres, v.102, p.265278, 1990.

FEARY, D.J. et al. Lawsonia intracellularis proliferative enteropathy in a foal. Schweizer Archiv fur Tierheilkdunde, Zurich, v.149, p.129-133, 2007.

FOX, J.G.; LAWSON, G.H.K. Campylobacter-like omega intracellular antigen in proliferative colitis of ferrets. Laboratory Animal Science, Londres, v.38, p.34-36, 1988.

FRANK, N. et al. Lawsonia intracellularis proliferative enteropathy in a weanling foal. Equine Veterinary Journal, Cambs, v.30, p.549-552, 1998. 
GUEDES, R.M.C. Porcine proliferative enteropathy: Diagnosis, immune response and pathogenesis. 2002. 261f. Tese (PhD em Patobiologia Veterinária) Programa de Pós-graduação em Veterinary PathoBiology, Collegue of Veterinary Medicine, University of Minnesota, Minnesota.

GUEDES, R.M.C. et al. Comparison of different methods for diagnosis of porcine proliferative enteropathy. Canadian Journal Veterinary Research, Ottawa, v.66, p.99-107, 2002a.

GUEDES, R.M.C. et al. Serologic follow-up of a repopulated swine herd after an outbreak of proliferative hemorrhagic enteropathy. Canadian Journal Veterinary Research, Ottawa, v.66, p.258-263, 2002b.

GUEDES, R.M.C.; GEBHART, C.J. Onset and duration of fecal shedding, cell-mediated and humoral immune response in pigs after challenge with a pathogenic isolate or a commercial vaccine of Lawsonia intracellularis. Veterinary Microbiology, Amsterdan, v.91, p.135-145, 2003.

HERBST, W. et al. Diagnosis of Lawsonia intracellularis using the polymerase chain reaction (PCR) in pigs with and without diarrhea and other animal species. Deutsche tierärztliche Wochenschrift, Berlim, v.110, p.361-364, 2003.

HOTCHKISS, C.E. et al. Proliferative enteropathy in rabbtis. Laboratory Animal Science, Londres, v.46, p.623-627, 1996

JONES, T.C. et al. Patologia veterinária. São Paulo: Manole, 2000. 1415p.

KLEIN, E.C. et al. Fatal outbreaks of proliferative enteritis caused by Lawsonia intracellularis in young colony-raised rhesus macaques. Journal of Medical Primatology, Covington, v.28, p.11-18, 1999.

KNITTEL, J.P. et al. Evaluation of ante-mortem polymerase chain reaction and serology methods for detection of Lawsonia intracellularis exposed pigs. American Journal Veterinary Research, Schaumburg, p.722-726, 1998.

LAVOIE, J.P. et al. Proliferative enteropathy in foals: A cause of colic, diarrhea, and protein-losing enteropathy. In: AMERICAN ASSOCIATION OF EQUINE PRACTITIONERS, 1998, Quebec, Canadá. Proceedings... Quebec: AAEP, 1998. v.44, p.134-135.

LAVOIE, J.P. et al. Equine proliferative enteropathy: A cause of weight loss, colic, diarrhea and hypoproteinaemia in foals on three breeding farms. Equine Veterinary Journal, Cambs, v.32, p.418-425, 2000

LAVOIE, J.P.; DROLET R. Proliferative enteropathy in foals. In: MAIR, T. et al. Manual of equine gastroenterology. Philadelphia: Saunders, 2002. p.508-509.

LAWSON, G.H.K.; GEBHART, C.J. Proliferative enteropathy. Journal of Comparative Pathology, Londres, v.122, p.77 $100,2000$.
LEMARCHAND, T.X. et al. Intracellular Campylobacter-like organisms associated with rectal proliferative enteroproctitis in emus (Dromaius novaehollandiae). Veterinary Pathology, Auburn, v.34, p.152-156, 1996.

McCLINTOCK, S.A.; COLLINS, A.M. Lawsonia intracellularis proliferative enteropathy in a weanling foal in Australia. Australian Veterinary Journal, St. Leonards, v.82, p.750752, 2004

McORIST, S. et al. Characterization of Lawsonia intracellularis gen. nov., sp. nov., the obligately intracellular bacterium of porcine proliferative enteropathy. International Journal of Systematic Bacteriology, Washington, v.45, p.820-825, $1995 \mathrm{a}$

McORIST, S. et al. Antimicrobial susceptibility of ileal symbiont intracellularis isolated from pigs with proliferative enteropathy. Journal Clinic Microbiology, Washington, v.33, p.13141317, 1995b.

MOON, H.W. et al. Intraepithelial vibrio associated with acute typhilitis of young rabbits. Veterinary Pathology, Auburn, v.11, p.313-326, 1974

MURRAY, M.J.; SMITH, B.P. Diseases of the alimentary tract. In: SMITH, B.P. Large animal internal medicine. St. Louis: Mosby, 2002. p.593-789.

REEF, V.B. Pediatric abdominal ultrasonography. In: Equine diagnostic ultrasound. Philadelphia: Saunders, 1998. p.364-403.

SAMPIERI, F. et al. Tetracycline therapy of Lawsonia intracellularis enteropathy in foals. Equine Veterinary Journal, Cambs, v.38, p.89-92, 2006.

SCHUMACHER, J. et al. Surgical and medical treatment of an Arabian filly with proliferative enteropathy caused by Lawsonia intracellularis. Journal of Veterinary Internal Medicine, Lakewood, v.14, p.630-632, 2000.

SMITH, D.G. et al. Gamma interferon influences intestinal epithelial hyperplasia caused by Lawsonia intracellularis infection in mice. Infection and Immunity, Washington, v.68, p.6737-6743, 2000

VANDENBERGHE, J. et al. Spontaneous adenocarcinoma of the ascending colon in Wistar rats: the intracytoplasmic presence of Campylobacter-like bacteria. Journal of Comparative Pathology, Londres, v.95, p.45-55, 1985.

WILLIAMS, N.M. et al. Proliferative enteritis in a foal caused by Lawsonia intracellularis like bacteria. Journal Veterinary Diagnostic Investigation, Davis, v.8, p.254-256, 1996.

WUERSCH, K. et al. Lawsonia intracellularis proliferative enteropathy in a filly. Journal Veterinary Medicine, series A. Physiology Pathology and Clinical Medicine, Oxford, v.53, p.17-21, 2006. 